\title{
Exercise Preconditioning-Induced Early and Late Phase of Cardioprotection Is Associated With Protein Kinase C Epsilon Translocation
}

\author{
Zhe Hao, PhD; Shan-Shan Pan, PhD; Yu-Jun Shen, PhD; Jun Ge
}

\begin{abstract}
Background: Exercise preconditioning (EP) can provide powerful protection to the heart. Evidence supports the contention that EP directly enhances myocardial tolerance to ischaemia through a protein kinase $\mathrm{C}$ (PKC)-mediated mechanism. However, studies investigating the role of isoform-specific PKC after EP are lacking.
\end{abstract}

\begin{abstract}
Methods and Results: In this study, a male Sprague-Dawley rat model of EP was established (4 periods of $30 \mathrm{~m} / \mathrm{min}$ for $10 \mathrm{~min}$ exercise then a $10 \mathrm{~min}$ rest at $0 \%$ grade treadmill exercise). Rats were subjected to exhaustive exercise to induce myocardial injury. Chelerythrine $(5 \mathrm{mg} / \mathrm{kg})$ was injected before EP to investigate the role of PKC in EP. EP was found to attenuate exhaustive exercise-induced myocardial injury in both of EP's 2 protective phases, especially the latter phase. After EP, PKC $\varepsilon$ was markedly upregulated, and PKC $\varepsilon$ was translocated to myocardial intercalated disks, and p-PKC $\varepsilon^{\operatorname{Ser} 729}$ was translocated to the myocardial cytomembrane. Even though PKC $\varepsilon$ was markedly upregulated and translocated to intercalated disks during exhaustive exercise, $\mathrm{p}-\mathrm{PKC} \varepsilon^{\mathrm{Ser} 22}$ was mainly distributed in the cytoplasm. A chelerythrine injection before EP did not suppress the activation of PKC and the protection of EP.
\end{abstract}

\begin{abstract}
Conclusions: These results indicate that $\mathrm{PKC} \varepsilon$ plays an important role in EP-mediated protection of the myocardium during exhaustive exercise-induced myocardial injury, and that a chelerythrine injection during exercise is not suitable for demonstrating the role of PKCe. (Circ $J$ 2014; 78: 1636-1645)
\end{abstract}

Key Words: Cardioprotection; Exercise preconditioning; Protein kinase C epsilon

$\mathbf{I}$ schemia/reperfusion $(\mathrm{I} / \mathrm{R})$ is one of the major causes of myocardial injury. Over the years, investigators have studied many approaches regarding the protection of the heart against I/R injury. Specifically, cardioprotection of ischemic preconditioning (IP) ${ }^{1}$ and remote $\mathrm{IP}^{2,3,4}$ were described as the immediate adaptation of the heart to brief sublethal ischemia but it lacking practical utility for providing protection to human. Recently, researchers have found that, like IP, exercise preconditioning (EP), which here refers to brief episodes of exercise, can also enhance the tolerance of the heart to subsequent ischemic insult. ${ }^{5,6}$ It is demonstrated here that EP has 2 distinct protective phases, the early phase, which occurs immediately after the exercise, and a late phase, which peaks $24 \mathrm{~h}$ after exercise. ${ }^{6-9}$ Although the powerful cardioprotective effect of EP has been proved, the intracellular mechanisms involved in this EP-conferred cardioprotection remain unclear. Recent evidence supports the contention that acute exercise directly enhances myocardial tolerance to ischemia in the hearts of rats through a protein kinase C (PKC)-mediated mechanism. ${ }^{5}$ However, studies investigating the role of isoform-specific alterations in PKC after EP are still rare. One recent study clearly demonstrated that the EP-induced early phase of cardioprotection requires $\mathrm{PKC} \delta$ translocation. ${ }^{8}$ In this study, which was performed by the present team, short-term adaptation of adult rats to EP was found to markedly increase the expression of $\mathrm{PKC} \delta$ and phosphorylation of PKC $\delta$. However, the PKCE responsible for EP has not been identified. In the present study, it was hypothesized that $\mathrm{EP}$ caused an increase in $\mathrm{PKC} \varepsilon$ expression and translocation of $\mathrm{PKC} \varepsilon$, and that the PKC inhibitor, chelerythrine (CHE), suppressed these events, thus attenuating the EP-mediated cardioprotection.

\section{Methods}

\section{Ethical Approval}

Adult (8-week-old) male Sprague-Dawley rats (Sippr BK, Shanghai, China) were housed at a constant temperature $\left(22 \pm 2^{\circ} \mathrm{C}\right)$ on a 12 -h light/dark cycle. They were fed ad libitum on standard laboratory rat chow and had free access to tap water. The investigation conforms to the Guide for the Care and Use of Laboratory Animals published by the US National Institutes of Health (NIH Publication no. 85-23, revised 1996) and was

Received December 18, 2013; revised manuscript received March 4, 2014; accepted March 25, 2014; released online April 28 , 2014

Time for primary review: 21 days

Department of Sports Anatomy, School of Sports Science, Shanghai University of Sport, Shanghai, China

Mailing address: Shan-Shan Pan, PhD, Department of Sports Anatomy, School of Sports Science, Shanghai University of Sport, 399

Changhai Road, Shanghai 200438, China. E-mail: panshanshan2013@163.com

ISSN-1346-9843 doi:10.1253/circj.CJ-13-1525

All rights are reserved to the Japanese Circulation Society. For permissions, please e-mail: cj@j-circ.or.jp 
approved by the Ethics Committee for Science Research at Shanghai University of Sport.

\section{Experimental Protocol}

All animals performed a light exercise familiarization on the treadmill for 5 consecutive days. The velocity on the treadmill was $15 \mathrm{~m} / \mathrm{min}$ and the exercise duration was for $10-20 \mathrm{~min} /$ day. The EP protocol was designed with minor modifications of the protocol described by Domenech et al. ${ }^{10}$ and Parra et al. ${ }^{6}$ On the seventh day, animals were randomly assigned to 10 experimental groups $(\mathrm{n}=25$ rats per group):

- Group C, Control: rats were placed on the treadmill without movement.

- Group EE, Exhaustive exercise: rats were acclimated to the treadmill at $30 \mathrm{~m} / \mathrm{min}$ with $0 \%$ grade till exhausted. Exhaustion was defined as the rat being unable to upright itself when placed on its back. Rats were sacrificed $0.5 \mathrm{~h}$ after exhaustion.

- Group EEP, Early exercise preconditioning: rats were acclimated to the treadmill at $30 \mathrm{~m} / \mathrm{min}$ with $0 \%$ grade for 4 periods of $10 \mathrm{~min}$ each, with intervening periods of rest that were $10 \mathrm{~min}$ long. Exercise began and ended with 5-min "warm up" and "cool down" periods at $15 \mathrm{~m} / \mathrm{min}$ with $0 \%$ grade. Rats were sacrificed $0.5 \mathrm{~h}$ after exercise.

- Group EEP+EE, Early exercise preconditioning plus exhaustive exercise: rats were treated as per Group EEP, where $0.5 \mathrm{~h}$ after exercise, rats were acclimated to the treadmill at $30 \mathrm{~m} / \mathrm{min}$ with $0 \%$ grade till exhausted. Rats were sacrificed $0.5 \mathrm{~h}$ after exhaustion.

- Group LEP, late exercise preconditioning: rats were acclimated to the treadmill at $30 \mathrm{~m} / \mathrm{min}$ with $0 \%$ grade for 4 periods of $10 \mathrm{~min}$ each, with intervening periods of rest that were $10 \mathrm{~min}$ long. Exercise began and ended with 5-min "warm up" and "cool down" periods at $15 \mathrm{~m} / \mathrm{min}$ with $0 \%$ grade. Rats were sacrificed $24 \mathrm{~h}$ after exercise.

- Group LEP+EE, Late exercise preconditioning plus exhaustive exercise: rats were treated as per Group LEP, where $24 \mathrm{~h}$ after exercise, rats were acclimated to the treadmill at $30 \mathrm{~m} / \mathrm{min}$ with $0 \%$ grade till exhausted. Rats were sacrificed $0.5 \mathrm{~h}$ after exhaustion.

- Group CHE+EEP+EE, CHE plus early exercise preconditioning plus exhaustive exercise: rats were treated as per Group EEP+EE, but CHE $(5 \mathrm{mg} / \mathrm{kg})$ was injected intraperitoneally, $10 \mathrm{~min}$ before exercise.

- Group CHE+LEP+EE, CHE plus late exercise preconditioning plus exhaustive exercise: rats were treated as per Group LEP+EE, but CHE was injected intraperitoneally $10 \mathrm{~min}$ before exercise.

Rats were anesthetized with trichloroacetaldehyde monohydrate $(400 \mathrm{mg} / \mathrm{kg}$, intraperitoneally), and then were fixed on an animal operation table in the dorsal position. The abdominal cavity was quickly opened, and the blood was drawn from the inferior caval vein. For histological analysis, the heart was exposed for perfusion fixation, as described previously. ${ }^{9}$ For Western blot analysis, ${ }^{11}$ the heart was rapidly excised, and the left ventricle free wall was isolated at the level of the near apex. Once the tissue was divided, the pieces were quick frozen in liquid nitrogen.

\section{Detection of Serum Cardiac Biomarkers}

Blood samples were centrifuged immediately after collection and the serum was separated. Serum cTnI levels were measured by using automated immunochemiluminescence on an Access 2 immunoassay system (Beckman Coulter, USA). This assay is based on a single-step sandwich principle, with paramagnetic particles coated as the solid phase and 2 monoclonal cTnI antibodies. ${ }^{8}$ The sensitivity threshold for cTnI was $0.01 \mathrm{~g} / \mathrm{L}$.

By using a double-antibody sandwich enzyme-linked immunosorbent assay (ELISA), the serum NT-proBNP levels were measured with a rat NT-proBNP ELISA kit (R\&D Systems, Minneapolis, MN, USA) according to the manufacturer's instructions. The sensitivity threshold for NT-proBNP was $1 \mathrm{~g} / \mathrm{L}$.

\section{Hematoxylin-Basic Fuchsin-Picric Acid (HBFP) Staining}

Rat hearts were measured by HBFP staining, as described previously. ${ }^{8}$ Five visual fields from each section, with 5 sections per group, totaling 25 visual fields, were randomly taken for morphometric analysis using the Image-Pro Plus software (Media Cybernetics, Silver Spring, MD, USA). The positive area and the integral optical density (IOD) were calculated.

\section{Transmission Electron Microscopy Analysis}

After the perfusion fixation, samples for the transmission electron microscopy analysis were taken from the tissue beneath the endocardial surface of the left ventricular anterior free wall at the level of the near apex, and prepared as previously described. ${ }^{9}$ Briefly, the tissue was fixed in paraformaldehyde and postosmicated in osmium tetroxide. After osmium fixation, the tissue was dehydrated, embedded, sectioned and stained with uranium acetate-lead citrate. Samples were examined and photographed with a transmission electron microscope $(\mathrm{H}-$ 800; Hitachi, Tokyo, Japan).

\section{Quantitative Real-Time Polymerase Chain Reaction}

Total RNA was extracted from LV tissue with Trizol. After DNase treatment, $1 \mathrm{mg}$ of total RNA samples was reversed transcribed with oligo primers and SuperScript ${ }^{\mathrm{TM}}$ III Reverse Transcriptase (Invitrogen, Carlsbad, CA, USA).

Quantification of cardiac gene expression was determined by using real-time polymerase chain reaction (RT-PCR). The RT-PCR was performed using a PKCE (Gene Bank Accession No.: NM_017171.1) specific forward primer (5'-CCAACTCTATTGCTGCTTCCA-3') and reverse primer (5'-CATGAGGTCTCCACCGTTTACA-3') to amplify the product. The samples were normalized using the housekeeping gene, glyceraldehyde 3-phosphate dehydrogenase (GAPDH) (Gene Bank Accession No. : NM_017008), using a forward primer (5'-GGAAAGCTGTGGCGTGAT-3') and reverse primer (5'-AAGGTGGAAGAATGGGAGTT-3'). The RT-PCR procedure was performed as previously described. ${ }^{12}$

\section{In Situ Hybridization Protocol}

In situ hybridization was performed using RNA probes for the $\mathrm{PKC} \varepsilon$ gene with the PKC $\varepsilon$ ISH assay kit (Boster Inc, Wuhan, China). The 3 mRNA-probes were:

(1) 5'-AAGCAACATCCATTCTTCAAGGAGATTGACTGGGT-3'

(2) 5'-ACCAAGAGAGATGTCAATAACTTTGACCAAGACTT-3'

(3) 5'-CAGATCAACCAGGAAGAATTCAAAGGCTTCTCCTA-3'

Briefly, after deparaffinization and dehydration, the sections were immersed in hydrogen peroxide for $10 \mathrm{~min}$ to block the endogenous peroxidase activity. After pretreatment steps, the target probe was applied and hybridized for $24 \mathrm{~h}$ at $40^{\circ} \mathrm{C}$. Thereafter, the amplification steps including application of biotinylation-linked digoxin labeling, were performed for $60 \mathrm{~min}$ at $37^{\circ} \mathrm{C}$ prior to DAB-visualization. 


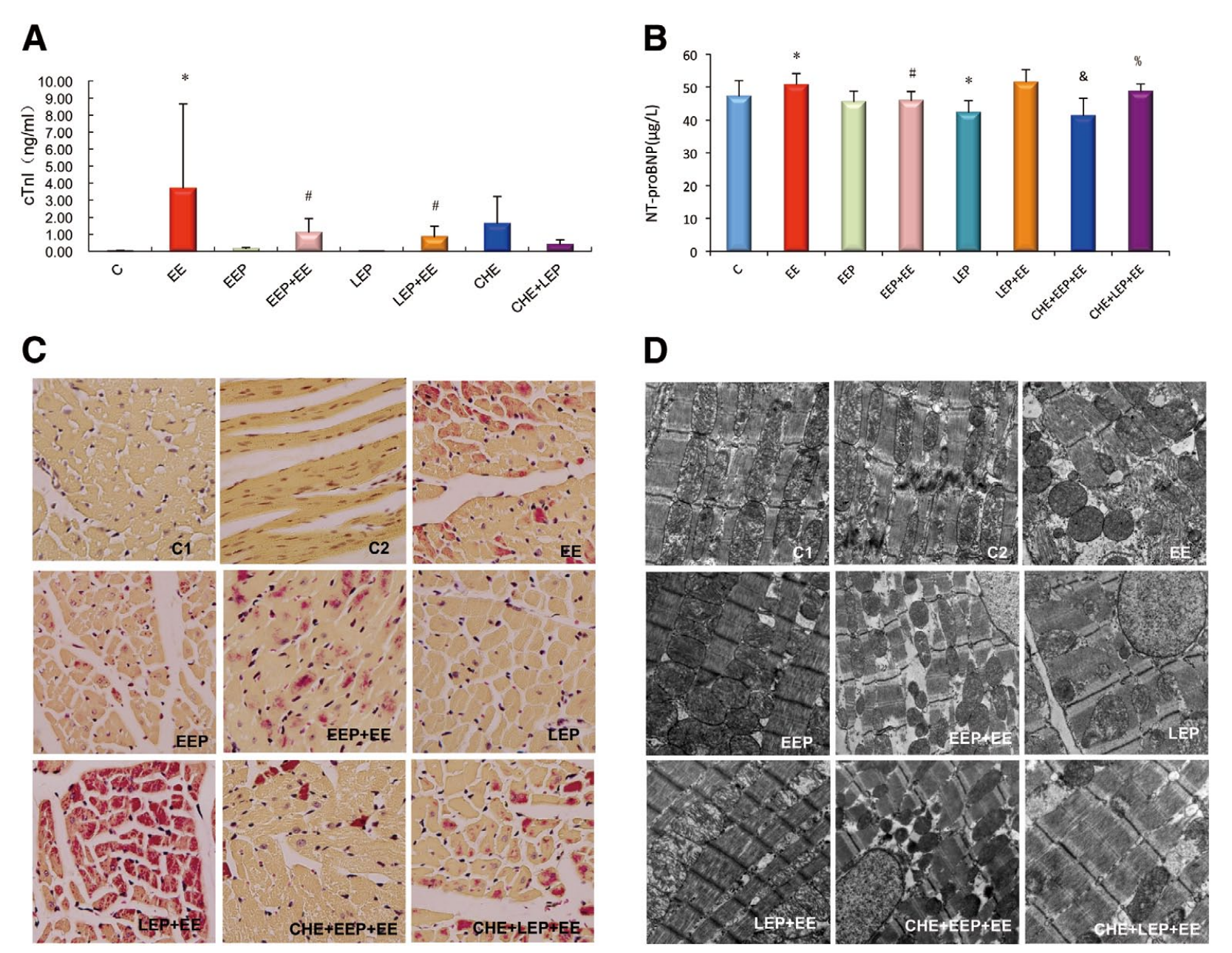

Figure 1. Early and late cardioprotection of EP against exhaustive exercise-induced myocardial injury. (A) Alterations of serum cTnl levels in the cardioprotection of EP. Significant differences $(P<0.05)$ are indicated as follows: from Group C $\left(^{*}\right)$, from Group EE (\#). (B) Alterations of serum NT-proBNP levels in the cardioprotection of EP. Significant differences $(P<0.05)$ are indicated as follows: from Group C (*), from Group EE (\#), from Group EEP+EE (\&), from Group LEP+EE (\%). (C) Myocardial ischemia detected by HBFP staining. The ischemic cardiomyocytes stained a vivid crimson red color in contrast to the light brown color of non-ischemic tissue. Ischemic cardiomyocytes that were stained crimson red were dominated in Group EE and Group LEP+EE, while only the red patchy stain was seen in Group EEP+EE, Group CHE+EEP+EE and Group CHE+LEP+EE. Cardiomyocytes in Group C (C1\&C2), Group EEP and Group LEP displayed a light brown color. Original magnification was $\times 400$. (D) Ultrastructural alteration of cardiomyocytes. Exhaustive exercise (EE) led to mitochondrial swelling, break or disappearance of the mitochondrial cristae, a diffused and less coherent Z-line, and wide interfibrillar space. EP alleviated exhaustive exercise-induced damage. The cardiomyocytes in Group EEP+EE and Group LEP+EE demonstrated damage to a lesser extent, involving alleviated intracellular edema and slight mitochondrial swelling. CHE did not abolish the protective effect of EP; similar results were observed in Group $\mathrm{CHE}+\mathrm{EEP}+\mathrm{EE}$ and Group $\mathrm{CHE}+\mathrm{LEP}+\mathrm{EE}$ where only a few vacuolated mitochondria were observed (original magnification $\times 10,000$ ). C, control; EE, exhaustive exercise; EEP, early exercise preconditioning; EEP+EE, early exercise preconditioning plus exhaustive exercise; LEP, late exercise preconditioning; LEP+EE, late exercise preconditioning plus exhaustive exercise; $\mathrm{CHE}+\mathrm{EEP}+\mathrm{EE}$, chelerythrine plus early exercise preconditioning plus exhaustive exercise; $\mathrm{CHE}+\mathrm{LEP}+\mathrm{EE}$, chelerythrine plus late exercise preconditioning plus exhaustive exercise; serum NT-proBNP, serum levels of N-terminal pro-hormone brain natriuretic peptide; HBFP, hematoxylin-basic fuchsin-picric acid.

\section{Immunohistochemistry}

Immunohistochemistry was performed, as described previous$1 \mathrm{y},{ }^{8}$ for the observation of PKC $\varepsilon$ in rat myocardium. Primary antibodies against $\mathrm{PKC} \varepsilon$ or $\mathrm{p}-\mathrm{PKC} \varepsilon^{\mathrm{Ser} 729}$, diluted at 1:50, were obtained from Santa Cruz (Santa Cruz Biotechnology, CA, USA), and incubated overnight at $4^{\circ} \mathrm{C}$ prior to detection using the streptavidin-biotin complex kit (Boster Bio-engineering, Wuhan, China), with a diaminobenzidine/peroxidase substrate to produce a brown color. The positive area and the IOD were calculated in the same way as that for HBFP staining.

\section{Western Blotting}

Western blotting was performed with a SDS-PAGE Electrophoresis System, as described previously. ${ }^{8}$ Primary antibodies against PKC $\varepsilon$ or p-PKC $\varepsilon^{\mathrm{Ser} 729}$ were obtained from Santa Cruz (1:3,000 dilution; Santa Cruz Biotechnology, Santa Cruz, CA, USA). Results were visualized with the enhanced chemiluminescence method and evaluated by ImageJ software $(\mathrm{NIH}$, 


\begin{tabular}{lccc} 
Table 1. Hematoxylin-Basic Fuchsin-Picric Acid (HBFP) & Staining & Image Analysis Results in Rat Myocardium \\
\multicolumn{1}{c}{ Group } & $\mathbf{n}$ & Positive area $\left(\boldsymbol{\mu \mathbf { m } ^ { 2 } )}\right.$ & IOD \\
C & 25 & 0 & 0 \\
EE & 25 & $55.26 \pm 6.91^{*}$ & $14092.39 \pm 1761.04^{*}$ \\
EEP & 25 & $11.27 \pm 4.52$ & $2873.89 \pm 1152.01$ \\
EEP+EE & 25 & $33.77 \pm 6.24^{\#}$ & $8610.24 \pm 1590.79^{\#}$ \\
LEP & 25 & 0 & 0 \\
LEP+EE & 25 & $69.09 \pm 14.79^{\#}$ & $17617.76 \pm 3770.28^{\#}$ \\
CHE+EEP+EE & 25 & $31.17 \pm 6.64$ & $7947.65 \pm 1691.97$ \\
CHE+LEP+EE & 25 & $43.65 \pm 8.26^{\$}$ & $11130.16 \pm 2107.04^{\$}$
\end{tabular}

Values are expressed as mean \pm SD. Significant differences $(P<0.05)$ are indicated as follows: from Group $C\left(^{*}\right)$, from Group EE (\#), from Group LEP+EE (\$).

$\mathrm{C}$, control; $\mathrm{CHE}+\mathrm{EEP}+\mathrm{EE}$, chelerythrine plus early exercise preconditioning plus exhaustive exercise; $\mathrm{CHE}+\mathrm{LEP}+\mathrm{EE}$, chelerythrine plus late exercise preconditioning plus exhaustive exercise; EE, exhaustive exercise; EEP, early exercise preconditioning; EEP+EE, early exercise preconditioning plus exhaustive exercise; IOD, integral optical density; LEP, late exercise preconditioning; LEP+EE, late exercise preconditioning plus exhaustive exercise.

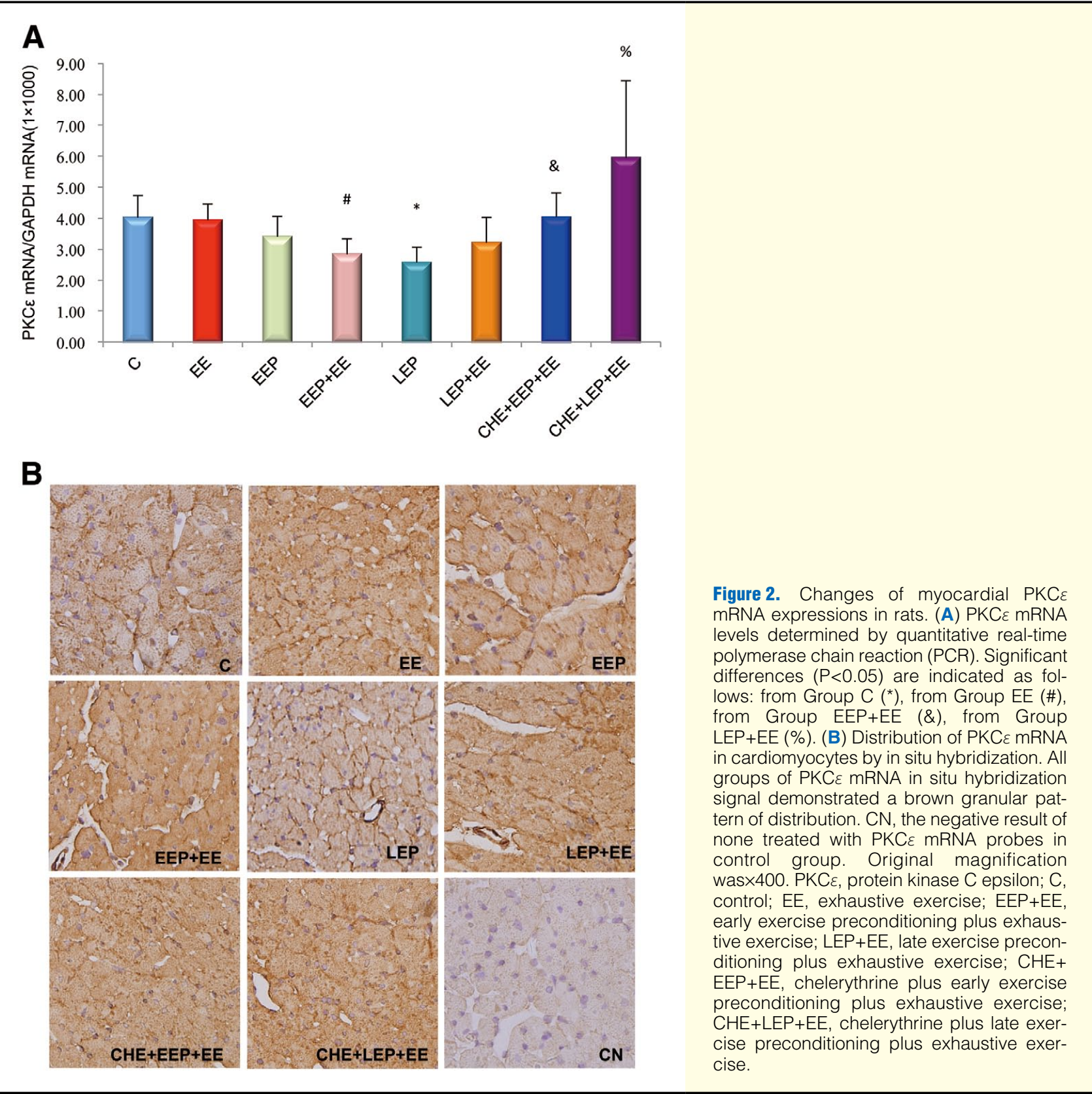




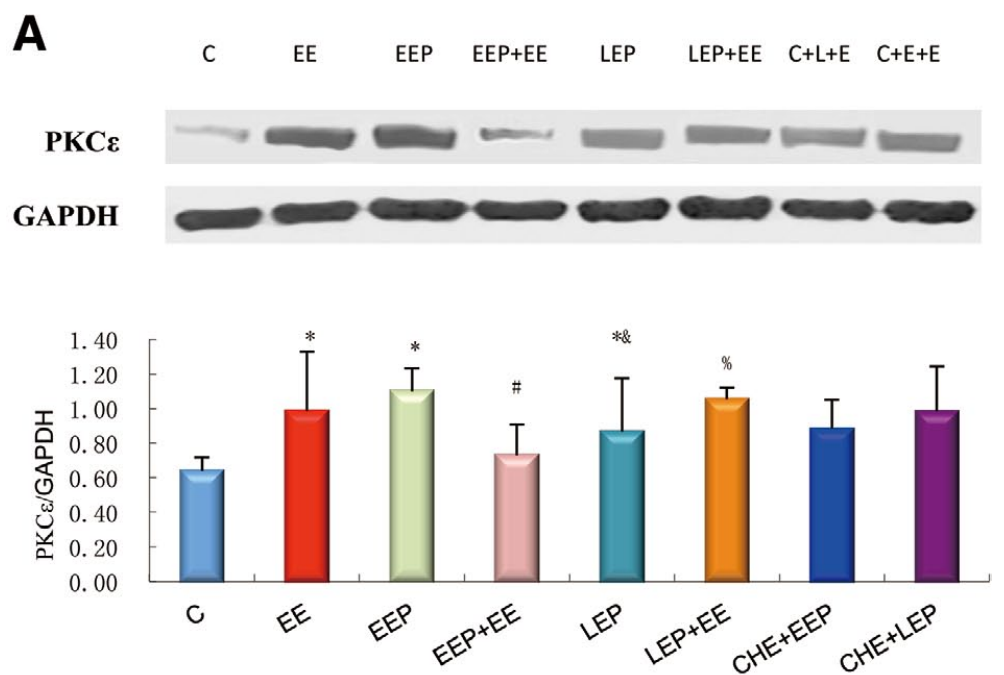

B
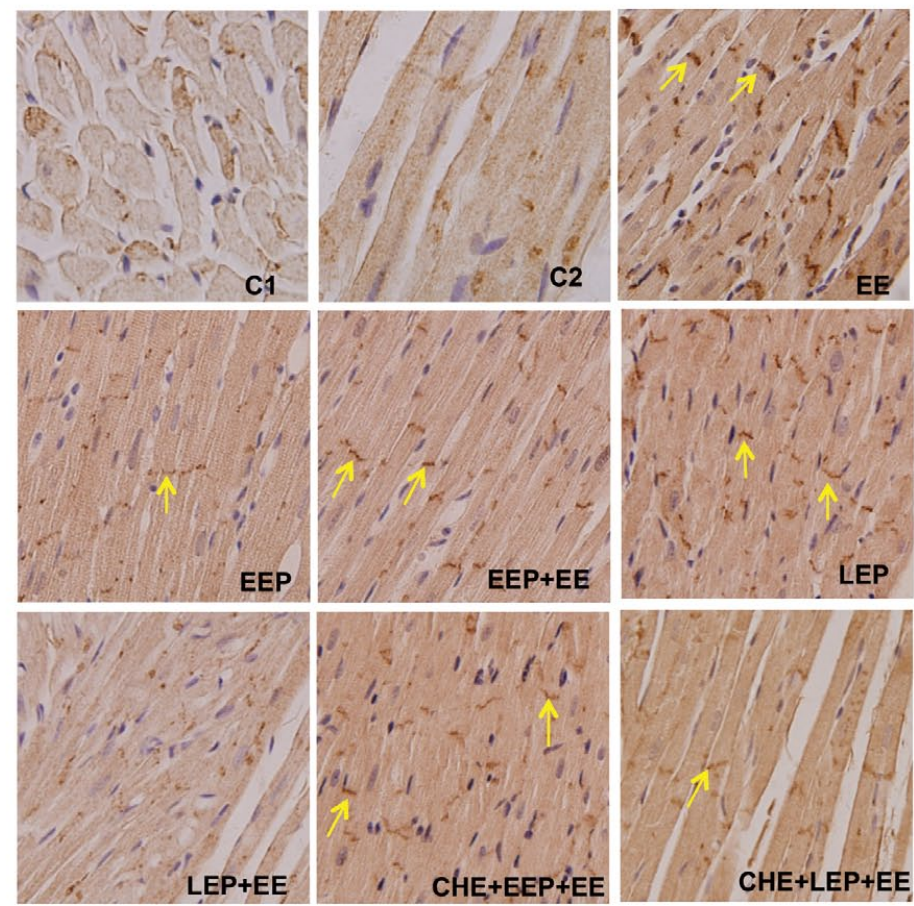

Figure 3. Changes of myocardium $\mathrm{PKC} \varepsilon$ expressions in rats. (A) Myocardial PKC $\varepsilon$ levels were determined by Western blotting. Values are presented as mean $\pm S D$. Significant differences $(P<0.05)$ are indicated as follows: from Group C $\left(^{*}\right)$, from Group EE (\#), from Group EEP (\&), from Group EEP+EE (\%). (B) Immunohistochemistry staining of $\mathrm{PKC} \varepsilon$ in cardiomyocytes. All groups of $\mathrm{PKC} \varepsilon$ positive immunoreactivity demonstrated a brownish color. C1\&C2 demonstrated the positive results of the control group; original magnification was $\times 1,000$. Arrowheads from the other groups indicated PKC $\varepsilon$ positive immunoreactivity localized to intercalated disks; original magnification was $\times 400$. PKC $\varepsilon$, protein kinase $C$ epsilon; $C$, control; EE, exhaustive exercise; EEP, early exercise preconditioning; $\mathrm{EEP}+\mathrm{EE}$, early exercise preconditioning plus exhaustive exercise; $\mathrm{CHE}+\mathrm{EEP}+\mathrm{EE}$, chelerythrine plus early exercise preconditioning plus exhaustive exercise; $\mathrm{CHE}+\mathrm{LEP}+\mathrm{EE}$, chelerythrine plus late exercise preconditioning plus exhaustive exercise.

Bethesda, MD, USA).

\section{Statistical Analysis}

Data were analysed using a one-way ANOVA (SPSS16.0; SPSS, Chicago, IL, USA) followed by the Student-NewmanKeuls comparison of groups. All results shown are significant $(\mathrm{P}<0.05)$, unless stated otherwise.

\section{Results}

\section{Early and Late Cardioprotective Effect of EP Against \\ Exhaustive Exercise}

The mean running distance to exhaustion for Group EE, Group $\mathrm{EEP}+\mathrm{EE}$ and Group CHE+EEP+EE were 2,657.37 \pm 975.57 $(\mathrm{n}=18), 2,058.00 \pm 852.28 \quad(\mathrm{n}=20)$, and $1,756.67 \pm 833.69 \mathrm{~m}$ $(\mathrm{n}=16)$, respectively, and no significant differences were de- tected between Group EE and Group EEP+EE (P=NS). Interestingly, the mean running distance to exhaustion for Group $\mathrm{LEP}+\mathrm{EE}$ and Group CHE+LEP+EE were 4,590.00 $\pm 1,582.82 \mathrm{~m}$ $(\mathrm{n}=20)$ and 4,512.00 $\pm 1,467.93 \mathrm{~m}(\mathrm{n}=20)$, respectively, and compared with Group EE, the mean running distance to exhaustion was significantly longer in Group LEP+EE and Group CHE+LEP+EE $(\mathrm{P}<0.05)$.

Serum cTnI levels (Figure 1A) in Group EE were significantly higher than in Group $\mathrm{C}(\mathrm{P}<0.05)$. Compared with Group $\mathrm{EE}$, serum cTnI levels in Group EEP+EE and Group LEP+EE decreased significantly $(\mathrm{P}<0.05)$.

Serum NT-proBNP levels (Figure 1B) in Group EE were significantly higher than those in Group $\mathrm{C}(\mathrm{P}<0.05)$. Compared with Group EE, serum NT-proBNP levels in Group EEP+EE decreased significantly $(\mathrm{P}<0.05)$. No significant differences were found between Group EE and Group LEP+EE $(\mathrm{P}=\mathrm{NS})$. 


\begin{tabular}{lccc} 
Table 2. Protein Kinase C Epsilon (PKC $\boldsymbol{\varepsilon})$ & Immunoreaction Image Analysis Results in Rat Myocardium \\
\multicolumn{1}{c}{ Group } & $\mathbf{n}$ & Positive area $\left(\boldsymbol{\mu \mathbf { m } ^ { 2 } )}\right.$ & IOD \\
C & 25 & $1.57 \pm 0.79$ & $401.53 \pm 200.34$ \\
EE & 25 & $3.48 \pm 1.06^{\star}$ & $886.62 \pm 271.16^{\star}$ \\
EEP & 25 & $1.52 \pm 0.72$ & $387.66 \pm 183.40$ \\
EEP+EE & 25 & $2.75 \pm 1.42^{\#}$ & $701.36 \pm 362.72^{\#}$ \\
LEP & 25 & $2.96 \pm 1.14^{\star}$ & $753.82 \pm 289.70^{\star} \$$ \\
LEP+EE & 25 & $2.16 \pm 1.44^{\#}$ & $551.55 \pm 368.07^{\#}$ \\
CHE+EEP+EE & 25 & $4.91 \pm 2.43^{\star}$ & $1252.75 \pm 619.28^{\star}$ \\
CHE+LEP+EE & 25 & $1.67 \pm 1.19$ & $426.11 \pm 296.52$
\end{tabular}

Significant differences $(P<0.05)$ are indicated as follows: from Group C $\left(^{*}\right)$, from Group EE (\#), from Group EEP+EE (\&), from Group EEP (\$).

Abbreviations as in Table 1.

Compared with Group EEP+EE, serum NT-proBNP levels in Group CHE+EEP+EE increased significantly $(\mathrm{P}<0.05)$. Compared with Group LEP+EE, serum NT-proBNP levels in Group $\mathrm{CHE}+\mathrm{EEP}+\mathrm{EE}$ decreased significantly $(\mathrm{P}<0.05)$.

HBFP stained images and image analysis (Table 1, Figure 1C) showed that the hypoxic and ischemic cardiomyocytes stained a vivid crimson red color in contrast to the light brown color of non-hypoxic and non-ischemic tissue. Cardiomyocytes in Group C and Group LEP displayed a light brown color while crimson red was seen in the majority of cases in Group EE and Group LEP+EE; the positive area and IOD of HBFP staining in Group EE were significantly increased compared with Group $\mathrm{C}(\mathrm{P}<0.05)$. In Group EEP, only the red spot stain was seen in a small fraction of cardiomyocytes. In Group $\mathrm{EEP}+\mathrm{EE}$, Group $\mathrm{CHE}+\mathrm{EEP}+\mathrm{EE}$ and Group CHE+LEP+EE, the red patchy stain was scattered across the cardiomyocytes. The positive area and IOD of HBFP staining in Group EEP+EE were significantly decreased compared with those in Group EE $(\mathrm{P}<0.05)$. Nevertheless, the 2 values in Group LEP+EE were significantly increased compared with those in Group EE $(\mathrm{P}<0.05)$. Compared with Group LEP+EE, the positive area and IOD of HBFP staining in Group CHE+LEP+EE were significantly decreased $(\mathrm{P}<0.05)$, but there were no significant differences in Group CHE+EEP+EE compared with Group EEP+EE.

The ultrastructure of cardiomyocytes from the left ventricular anterior free wall showed that normal cardiomyocytes in Group $\mathrm{C}$ were mainly characterized by well-arranged myofibrils, intercalated discs and mitochondria, and cardiomyocytes in Group EEP and Group LEP (Figure 1D), which was similar to those described in Group C. In Group EE, exhaustive exercise led to mitochondrial swelling, break and disappearance of the mitochondrial cristae, a diffused and less coherent Z-line, wide interfibrillar space, and EP-alleviated exhaustive exercise-induced damage. The cardiomyocytes in Group EEP+EE and Group LEP+EE demonstrated damage to a lesser extent; only a few vacuolated mitochondria were observed. Similar results were observed in Group $\mathrm{CHE}+\mathrm{EEP}+\mathrm{EE}$ and Group $\mathrm{CHE}+\mathrm{LEP}+\mathrm{EE}$.

mRNA Expression of PKC $\varepsilon$ in the Cardioprotective Effect of EP The PKCe RT-PCR results (Figure 2A) and in situ hybridization results (Figure 2B) showed that, compared with Group C, PKC $\varepsilon$ mRNA levels decreased significantly in Group LEP $(\mathrm{P}<0.05)$, but there were no significantly change in Group EE and Group EEP. Compared with Group EE, PKCe mRNA levels decreased significantly in Group EEP+EE $(\mathrm{P}<0.05)$. Compared with Group EEP+EE, PKC $\varepsilon$ mRNA levels increased significantly in Group $\mathrm{CHE}+\mathrm{EEP}+\mathrm{EE}(\mathrm{P}<0.05)$, and the same result was found between Group LEP+EE and Group $\mathrm{CHE}+\mathrm{LEP}+\mathrm{EE}(\mathrm{P}<0.05)$.

\section{Protein Expression of PKC $\varepsilon$ in the Cardioprotective Effect of EP}

Western blot results showed that compared with Group C, PKC $\varepsilon$ levels increased robustly in Group EE, Group EEP and Group LEP $(\mathrm{P}<0.05$; Figure 3A). Compared with Group EE, PKC $\varepsilon$ levels decreased significantly in Group EEP+EE $(\mathrm{P}<0.05)$. Compared with Group EEP+EE, PKC $\varepsilon$ levels increased robustly in Group LEP+EE $(\mathrm{P}<0.05)$. Compared with Group EEP+EE, $\mathrm{PKC} \varepsilon$ levels increased robustly in Group LEP+EE $(\mathrm{P}<0.05)$. In addition, we did not find any significant difference in the $\mathrm{PKC} \varepsilon$ level between Group EEP+EE and Group CHE+EEP+EE; the same result was also found between Group LEP+EE and Group CHE+LEP+EE.

The $\mathrm{PKC} \varepsilon$ immunohistochemistry results revealed that in Group C, PKC $\varepsilon$ was localized and showed a cytosolic diffuse pattern; this result is highly consistent with previously published data (Figure 3B). Compared with Group C, the pattern of PKC $\varepsilon$ changed in other groups except for Group LEP+EE, which $\mathrm{PKC} \varepsilon$ was preferentially localized to intercalated disks. Immunoreaction image analysis of $\mathrm{PKC} \varepsilon$ revealed that in comparison with Group C, a positive reaction of PKC $\varepsilon$ was markedly increased in Group EE, Group EEP and Group LEP $(\mathrm{P}<0.05)$; compared with Group EE, a positive reaction significantly decreased in Group EEP+EE and Group LEP+EE $(\mathrm{P}<0.05)$. The opposite result was found between Western blot and immunoreaction image analysis where it was shown that in comparison with Group EEP, PKC $\varepsilon$ was markedly increased in Group LEP $(\mathrm{P}<0.05)$. Interestingly, compared with Group EEP+EE, a positive reaction significantly increased in Group CHE+EEP+EE $(\mathrm{P}<0.05)$, but the results were adverse between Group LEP+EE and Group CHE+LEP+EE (Table 2).

\section{Protein Expression of p-PKC $\varepsilon^{\operatorname{Ser} 729}$ in the Cardioprotective Effect of EP}

The p-PKC $\varepsilon^{\mathrm{Ser} 729}$ Western blotting results are presented in

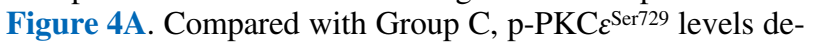
creased robustly in Group EEP $(\mathrm{P}<0.05)$, but there was no significant change in Group EE and Group LEP. Compared with Group EE, p-PKC $\varepsilon^{\text {Ser729 }}$ levels decreased significantly in Group $\mathrm{EEP}+\mathrm{EE}(\mathrm{P}<0.05)$. Compared with Group EEP, p-PKC $\varepsilon^{\mathrm{Ser} 729}$ levels increased significantly in Group LEP $(\mathrm{P}<0.05)$. Compared with Group EEP+EE, p-PKC $\varepsilon^{\text {Ser729 }}$ levels increased robustly in Group LEP+EE $(\mathrm{P}<0.05)$. Compared with Group LEP+EE, p-PKC $\varepsilon^{\text {Ser729 }}$ levels decreased significantly in Group $\mathrm{CHE}+\mathrm{LEP}+\mathrm{EE}(\mathrm{P}<0.05)$. 


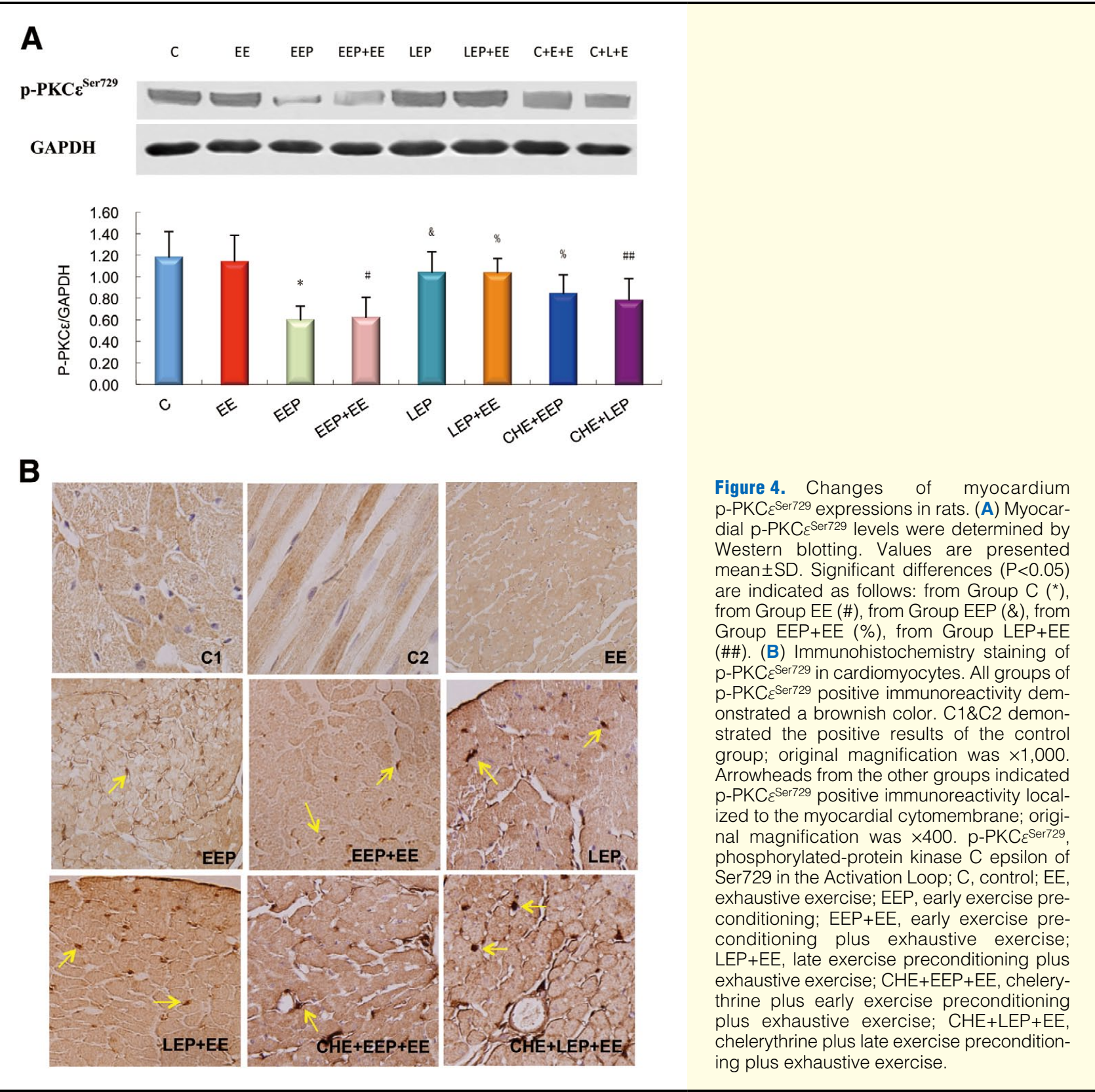

The p-PKC $\varepsilon^{\mathrm{Ser} 729}$ immunohistochemistry results (Figure 4B) revealed that in Group $\mathrm{C}$, the $\mathrm{p}-\mathrm{PKC} \varepsilon^{\mathrm{Ser} 729}$ was localized and showed a cytosolic diffuse pattern, and compared with Group $\mathrm{C}$, the pattern of $\mathrm{p}-\mathrm{PKC} \varepsilon^{\mathrm{Ser} 729}$ changed in Group EEP, EEP+EE, Group LEP, Group LEP+EE, Group CHE+EEP+EE and Group $\mathrm{CHE}+\mathrm{LEP}+\mathrm{EE}$, in which $\mathrm{p}-\mathrm{PKC} \varepsilon^{\mathrm{Ser} 729}$ was preferentially localized to the cytomembrane. Immunoreaction image analysis of $\mathrm{p}-\mathrm{PKC} \varepsilon^{\mathrm{Ser} 729}$ revealed that there were no significant differences among Group C, Group EE, Group EEP and Group LEP (Table 3). However, in comparison with Group EEP, a positive reaction of $\mathrm{p}-\mathrm{PKC} \varepsilon^{\mathrm{Ser} 729}$ was markedly increased in Group LEP $(\mathrm{P}<0.05)$. Interestingly, compared with Group LEP+EE, a positive reaction significantly increased in Group CHE+LEP+EE $(\mathrm{P}<0.05)$, which was opposite to the results found with Western blot result.

\section{Discussion}

The present study tested 2 hypotheses. The first is that exhaustive exercise-induced myocardial injury can be attenuated by only 1 bout of EP. The second is that EP affects PKC $\varepsilon$ translocation or activation. The main findings were that EP could induce cardioprotection in direct proportion with the increase of PKCE expression and translocation from cardiomyocytes to myocardial cell membranes.

\section{Early and Late Cardioprotective Effect of EP Against Exhaustive Exercise}

Exercise could enhance sustained relaxation to endotheliumdependent agonist stimulation in small arteries of control and ischemic hearts by enhancing nitric oxide contribution; endothelial $\mathrm{Ca}^{2+}$ responses have already been proven. ${ }^{13,14}$ Some re- 


\begin{tabular}{|lccc|}
\hline \multicolumn{5}{|c|}{$\begin{array}{c}\text { Table 3. Phosphorylated-Protein Kinase C Essilon of Ser729 in the Activation Loop (p-PKC } \boldsymbol{\varepsilon}^{\text {Ser729) }} \\
\text { Immunoreaction Image Analysis Results in Rat Myocardium }\end{array}$} \\
Group & $\mathbf{n}$ & Positive area $\left(\boldsymbol{\mu \mathbf { m } ^ { 2 } )}\right.$ & IOD \\
C & 25 & $1.63 \pm 1.33$ & $415.95 \pm 339.90$ \\
EE & 25 & $1.04 \pm 0.71$ & $264.49 \pm 182.16$ \\
EEP & 25 & $1.47 \pm 1.33$ & $374.41 \pm 339.83$ \\
EEP+EE & 25 & $1.32 \pm 1.31$ & $335.52 \pm 334.87$ \\
LEP & 25 & $2.25 \pm 1.52^{*}$ & $574.33 \pm 387.23^{*}$ \\
LEP+EE & 25 & $1.23 \pm 0.84$ & $313.30 \pm 213.54$ \\
CHE+EEP+EE & 25 & $1.04 \pm 0.44$ & $265.69 \pm 113.27$ \\
CHE+LEP+EE & 25 & $5.67 \pm 2.48^{*}$ & $1445.21 \pm 632.70^{*}$ \\
\hline
\end{tabular}

Significant differences $(\mathrm{P}<0.05)$ are indicated as follows: from Group EEP $\left({ }^{*}\right)$, from Group LEP+EE $(\%)$.

Abbreviations as in Table 1.

searchers have found that EP can attenuate myocardial infarction area in rats and dogs; $;, 6$ our recent study showed that the 1 bout of EP could attenuate myocardial injury induced by exhaustive exercise, but this cardioprotection was only observed during the early phase of EP. ${ }^{8}$ Therefore, the present study addressed whether EP could attenuate myocardial injury induced by exhaustive exercise during the late phase of EP. In this experiment, serum cTnI increased after rats underwent exhaustive exercise. However, during the early and late cardioprotective phases of EP, the rats that underwent exhaustive exercise showed decreased levels of serum cTnI. Myocardial HBFP staining data also showed that ischemic cardiomyocytes with crimson red dominated in Group EE, which indicated that rats in Group EE had myocardial anoxia or ischemia. But the present study hypothesis was slightly different from previous ideas about HBFP staining involving Group LEP+EE. This phenomenon might have been observed because the rats in Group $\mathrm{LEP}+\mathrm{EE}$ underwent longer durations of treadmill exercises. In addition, we found that the extent of myocardial morphologic changes was not consistent with the level of serum NT-proBNP. Serum NT-proBNP data showed that Group LEP+EE had greater systolic wall stress during exercise. Similarly, some researchers found that the dynamics of NT-proBNP changes during and after ergometric exercises cannot be used for the diagnosis of exercise-induced heart injury. ${ }^{15,16}$ Therefore, it is reasonable to attribute the increased exercise capacity, at least in part, to an enhanced tolerance of the heart to ischemic insults. However, the severity of myocardial hypoxia and ischemia does not always match the severity of myocardial injury. Our results showed that prolonged exercise did not result in more severe ischemia/hypoxia and ultrastructural damage in cardiomyocytes. Taken together, these data indicate that EP can induce cardioprotection against exhaustive exercise during both the early and late phases of EP.

\section{EP-Induced Early and Late Phase of Cardioprotection Is Associated With PKC $\varepsilon$ Translocation}

EP protects the heart from left ventricular dysfunction, oxidative injury, mitochondrial damage, and cell death., ${ }^{77}$ But the molecular mechanisms that mediate the powerful cardioprotective effect of EP remain to be elucidated. Several studies have shown that EP increased the expression of some myocardial proteins, such as heat shock proteins, ${ }^{18}$ mitochondrial and sarcolemmal ATP-sensitive potassium channels (mitoKATP or sarcKATP), ${ }^{19}$ cyclooxygenase- $2,{ }^{20}$ and endoplasmic reticulum stress proteins, ${ }^{7}$ which can attenuate many types of heart injuries. It has also been demonstrated that, in IP, PKC modulates its downstream proteins and regulates KATP channels, myocar- dial metabolism, and subsequent tissue oncosis. ${ }^{21} \mathrm{We}$ originally hypothesized that $\mathrm{PKC} \varepsilon$ immunoreactivity might increase after $\mathrm{EP}$, and was based in part on widespread experimental evidence supporting a cardioprotective role for PKC $\varepsilon$ in a setting of IP, preventing decreases in infarct size after IP. ${ }^{22}$ The signaling pathways responsible for cardioprotection have been shown to involve regulation of the opening of both sarcKATP and mitoKATP channels, the mitochondrial permeability transition pore, and connexin 43(Cx43). Application of $\psi \varepsilon$ RACK potentiates sarcKATP during ischemia, which can reduce the rate of entry of $\mathrm{Ca}^{2+}$ into the cytosol and the preservation of ATP. ${ }^{23}$ Carson and Korzick found that exercise can activate PKC $\varepsilon$ in a manner similar to IP, even though 1 bout of exercise can lead to decreases in total PKC $\varepsilon .{ }^{24}$ However, phosphorylated PKCE (p-PKC $\varepsilon^{\text {Ser729, }}$, phosphorylation of Ser729 in the activation loop) in the myocardium was increased, and increases in $\mathrm{p}-\mathrm{PKC} \varepsilon^{\mathrm{Ser} 729}$ might activate its substrates to evoke cardioprotection.

The present study results show that EP can urge PKC $\varepsilon$ translocated to intercalated disks (including immediately after EP and $24 \mathrm{~h}$ after EP). With PKC $\varepsilon$ translocated to intercalated disks, the exhaustive-exercise-induced myocardial injury was significantly attenuated by the early phase of EP, indicating that intercalated disks might be downstream targets of $\mathrm{PKC} \varepsilon$ during the early phase of EP. This result was the same as those found by other studies, which showed that, upon activation, PKCE translocated to multiple subcellular sites such as intercalated disks. ${ }^{25,26}$ Enhanced binding of $\mathrm{PKC} \varepsilon$ to $\mathrm{Cx} 43$, a major gap junction (GJ) protein, might be the cause of $\mathrm{PKC} \varepsilon$ translocating to intercalated disks. ${ }^{27}$ Phosphorylation of $\mathrm{Cx} 43$ by PKC $\varepsilon$ plays a crucial role in $\delta$-opioid-induced suppression of GJ permeability in ischemic myocardium. ${ }^{28}$ During the late phase of EP, $\mathrm{PKC} \varepsilon$ did not translocate to intercalated disks, but myocardial injury was still significantly attenuated, as it was during the early phase of EP. The cause of this might be related to PKCe phosphorylation. The activity and intracellular localization of members of the PKC family are controlled by phosphorylation at 3 highly conserved sites in the catalytic kinase domain. Phosphorylation of the $\mathrm{COOH}$-terminal hydrophobic priming site Ser729 of PKCE increases kinase activity, and the absence of phosphorylation at this priming site reduces kinase activity. ${ }^{29}$ These all indicate that $\mathrm{p}-\mathrm{PKC} \varepsilon^{\mathrm{Ser} 729}$ plays an important role in cardioprotection against I/R injury. The present study results showed that EP could cause p-PKC $\varepsilon^{\text {Ser729 }}$ to translocate to the cytoplasmic membrane (both immediately after EP and $24 \mathrm{~h}$ after $\mathrm{EP})$. With p-PKC $\varepsilon^{\mathrm{Ser} 729}$ localized at the cytoplasmic membrane, the exhaustive exercise-induced myocardial injury was significantly attenuated by EP, especially during the late phase. However, after exhaustive exercise, no translocation of $\mathrm{p}-\mathrm{PKC} \varepsilon^{\mathrm{Ser} 729}$ 
took place, and myocardial injury was sustained. From these results, which indicated that $\mathrm{p}-\mathrm{PKC} \varepsilon^{\mathrm{Ser} 729}$ was key to induced cardioprotection, it was found that $\mathrm{p}-\mathrm{PKC} \varepsilon^{\mathrm{Ser} 729}$ could phosphorylate cytoplasmic membrane proteins such as CX43 and that the phosphorylation of CX43 could decrease cardiomyocyte GJ permeability, prevent the spreading of injury between conjoined cells and finally enhance resistance to ischemic injury. ${ }^{30}$ Phosphorylation by $\mathrm{PKC} \varepsilon$ opens mitoK $\mathrm{ATP}$ channels, preserving mitochondrial function and generating local ROS, ${ }^{31}$ which can further activate $\mathrm{PKC} \varepsilon$ in a positive feedback mechanism and confer cardioprotection. ${ }^{19}$

A significant quantitative difference in $\mathrm{PKC} \varepsilon$ and $\mathrm{p}-\mathrm{PKC} \varepsilon^{\mathrm{Ser} 729}$ was observed between the early and late phases of EP. The present data show that $\mathrm{PKC} \varepsilon$ and $\mathrm{p}-\mathrm{PKC} \varepsilon^{\mathrm{Ser} 729}$ were significantly higher in Group LEP+EE than in Group EEP+EE, but there was little difference between Group EEP and Group LEP. These results indicate that longer periods of treadmill exercise might lead to increases in $\mathrm{PKC} \varepsilon$ and $\mathrm{p}-\mathrm{PKC} \varepsilon^{\mathrm{Ser} 729}$. However, exhaustive exercise also induced high $\mathrm{PKC} \varepsilon$ levels and translocation of PKC $\varepsilon$ to interacted disks, but p-PKC $\varepsilon^{\mathrm{Ser} 729}$ remained mainly in the cytoplasm and was distributed in a diffuse pattern. The reason why exhaustive exercise induced the translocation of $\mathrm{PKC} \varepsilon$ to intercalated disks is still unknown, but these results suggest that $\mathrm{p}-\mathrm{PKC} \varepsilon^{\mathrm{Ser} 729}$ is essential to the cardioprotection that it confers.

It was originally hypothesized that $\mathrm{PKC} \varepsilon \mathrm{mRNA}$ might also increase following $\mathrm{EP}$, in part based on experimental evidence that the important role of PKC $\varepsilon$ in a setting of preventing infarct size reduction followed IP. On the contrary, the present study results show that EP downregulated PKC $\varepsilon$ mRNA levels (both immediately after EP and $24 \mathrm{~h}$ after EP). This was consistent with the results from a study by Carson and Korzick where the research showed that significant decreases were found in myocardial PKC $\varepsilon$ mRNA levels immediately and $24 \mathrm{~h}$ after 1 bout of acute exercise. ${ }^{24}$ This and the assessments of PKC $\varepsilon$ protein expression, which showed protein $\mathrm{PKC} \varepsilon$ to be highly expressed during $\mathrm{EP}$, showed that $\mathrm{PKC} \varepsilon$ mRNA undergoes downregulation upon sustained stimulation. The molecular mechanisms underlying the downregulation of PKC are still unclear, but studies showed that chronic activation of PKC eventually results in the complete dephosphorylation and degradation of the enzyme by a ubiquitin/proteasome-dependent mechanism, which we here refer to as downregulation. ${ }^{32,33}$ Therefore, cardioprotection afforded by EP might be mainly attributable to the translation of $\mathrm{PKC} \varepsilon$ and not to the transcription of $\mathrm{PKC} \varepsilon$.

\section{The Opposite Effect of CHE}

$\mathrm{CHE}$ is a non-specific catalytic inhibitor of $\mathrm{PKC},{ }^{34}$ which was found to attenuate $\mathrm{PKC}$ phosphorylation and translocation from cytosol to the membrane or nucleus. ${ }^{35}$ During exercise, CHE suppressed the activation of 3 exercise-induced $\mathrm{PKC}$ isoforms $(\mathrm{PKC} \alpha, \mathrm{PKC} \delta$, and $\mathrm{PKC} \varepsilon$ ) and attenuated the exercise-mediated reduction of myocardial injury size during ischemia-reperfusion injury. ${ }^{18}$ However, recent studies by the present team have shown CHE to have no effect on the cardioprotective effects of $\mathrm{EP}$, and $\mathrm{CHE}$ did not attenuate the expression of $\mathrm{PKC} \delta$ or p-PKC $\delta^{\text {Thr507 }}$ proteins during EP. ${ }^{8}$ In fact, the influence of CHE on the cardioprotective effect is still a point of controversy. A study has found that the pharmacological inhibition of PKC before ischemia induced cardioprotection by reducing intracellular sodium overload via increases in Na-K-ATPase activity. ${ }^{36}$ The observation was consistent with the present study results, which showed that $\mathrm{CHE}$ did not abolish the translocation of $\mathrm{PKC} \varepsilon$ or $\mathrm{p}-\mathrm{PKC} \varepsilon^{\mathrm{Ser} 729}$, and unexpectedly increased the expression of $\mathrm{PKC} \varepsilon$ and $\mathrm{p}-\mathrm{PKC} \varepsilon^{\mathrm{Ser} 729}$ during both protective phases of EP. Moreover, CHE did not attenuate the protective effect of EP, which adversely had a protective effect on EP. These phenomena might be associated with the mechanisms independent of PKC inhibition, and other signal transduction events during EP should also be evaluated as possible causes of the effects described above.

\section{Conclusions}

In summary, the current study results demonstrate that EP can attenuate exhaustive exercise-induced myocardial injury in the early and the late phases of cardioprotection, especially during the late phase of EP. After EP, PKC $\varepsilon$ was markedly upregulated, $\mathrm{PKC} \varepsilon$ was translocated to myocardial intercalated disks, and $\mathrm{p}-\mathrm{PKC} \varepsilon^{\mathrm{Ser} 729}$ was translocated to the myocardial cytoplasmic membrane. No translocation of p-PKC $\varepsilon^{\mathrm{Ser} 729}$ was observed in the hearts of rats after exhaustive exercise. These results show that the translocation of $\mathrm{p}-\mathrm{PKC} \varepsilon^{\mathrm{Ser} 729}$ plays an important role in EP-conferred cardioprotection. Injection of the PKC inhibitor, $\mathrm{CHE}$, before EP failed to attenuate the cardioprotective effect of EP, suggesting that a CHE injection during exercise might not be an appropriate means of demonstrating the role of $\mathrm{PKC} \varepsilon$.

\section{Acknowledgments}

This work was supported by the National Natural Science Foundation of China (No. 31071031), and the Science and Technology Commission of Shanghai Municipality (No. 09490503300).

\section{References}

1. Murry CE, Jennings RB, Reimer KA. Preconditioning with ischemia: A delay of lethal cell injury in ischemic myocardium. Circulation 1986; 74: $1124-1136$

2. Yetgin T, Manintveld OC, Boersma E, Kappetein AP, van Geuns RJ, Zijlstra F, et al. Remote ischemic conditioning in percutaneous coronary intervention and coronary artery bypass grafting: Meta-analysis of randomized trials. Circ J 2012; 76: 2392-2404.

3. Hong DM, Jeon Y, Lee CS, Kim HJ, Lee JM, Bahk JH, et al. Effects of remote ischemic preconditioning with postconditioning in patients undergoing off-pump coronary artery bypass surgery: Randomized controlled trial. Circ J 2012; 76: 884-890.

4. Minamino T. Cardioprotection from ischemia/reperfusion injury: Basic and translational research. Circ J 2012; 76: 1074-1082.

5. Yamashita N, Baxter GF, Yellon DM. Exercise directly enhances myocardial tolerance to ischaemia-reperfusion injury in the rat through a protein kinase $\mathrm{C}$ mediated mechanism. Heart 2001; 85: 331-336.

6. Parra VM, Macho P, Domenech RJ. Late cardiac preconditioning by exercise in dogs is mediated by mitochondrial potassium channels. $J$ Cardiovasc Pharmacol 2010; 56: 268-274.

7. Powers SK, Quindry JC, Kavazis AN. Exercise-induced cardioprotection against myocardial ischemia-reperfusion injury. Free Radic Biol Med 2008; 44: 193-201.

8. Shen YJ, Pan SS, Ge J, Hao Z. Exercise preconditioning provides early cardioprotection against exhaustive exercise in rats: Potential involvement of protein kinase $\mathrm{C}$ delta translocation. Mol Cell Biochem 2012; 368: 89-102.

9. Shen YJ, Pan SS, Zhuang T, Wang FJ. Exercise preconditioning initiates late cardioprotection against isoproterenol-induced myocardial injury in rats independent of protein kinase C. J Physiol Sci 2011; 61: $13-21$.

10. Domenech R, Macho P, Schwarze H, Sanchez G. Exercise induces early and late myocardial preconditioning in dogs. Cardiovasc Res 2002; 55: 561-566.

11. Antunes-Neto JM, Toyama MH, Carneiro EM, Boschero AC, Pereira-da-Silva L, Macedo DV. Circulating leukocyte heat shock protein 70 (HSP70) and oxidative stress markers in rats after a bout of exhaustive exercise. Stress 2006; 9: 107-115.

12. Kawata H, Yoshida K, Kawamoto A, Kurioka H, Takase E, Sasaki $\mathrm{Y}$, et al. Ischemic preconditioning upregulates vascular endothelial growth factor mRNA expression and neovascularization via nuclear translocation of protein kinase $C$ epsilon in the rat ischemic myocardium. Circ Res 2001; 88: 696-704.

13. Heaps CL, Robles JC, Sarin V, Mattox ML, Parker JL. Exercise 
training-induced adaptations in mediators of sustained endotheliumdependent coronary artery relaxation in a porcine model of ischemic heart disease. Microcirculation 2014 January 22, doi:10.1111/ micc.12116 [Epub ahead of print].

14. Ozasa N, Morimoto T, Bao B, Shioi T, Kimura T. Effects of machineassisted cycling on exercise capacity and endothelial function in elderly patients with heart failure. Circ J 2012; 76: 1889-1894.

15. Bartek J, Stejskal D, Lacnak B, Jurakova R. Application of determined NT-proBNP in physical standardized exercise. Biomed Pap Med Fac Univ Palacky Olomouc Czech Repub 2003; 147: 71-75.

16. De Greef J, Funk M, Vermaak WJ, Perumal NS, Libhaber CD, Vangu MD. NT-proBNP and the diagnosis of exercise-induced myocardial ischaemia. Cardiovasc J Afr 2008; 19: 264-267.

17. de Waard MC, van der Velden J, Bito V, Ozdemir S, Biesmans L, Boontje NM, et al. Early exercise training normalizes myofilament function and attenuates left ventricular pump dysfunction in mice with a large myocardial infarction. Circ Res 2007; 100: 1079-1088.

18. Melling CW, Thorp DB, Milne KJ, Noble EG. Myocardial Hsp70 phosphorylation and PKC-mediated cardioprotection following exercise. Cell Stress Chaperones 2009; 14: 141-150.

19. Quindry JC, Miller L, McGinnis G, Kliszczewicz B, Irwin JM, Landram M, et al. Ischemia reperfusion injury, KATP channels, and exercise-induced cardioprotection against apoptosis. J Appl Physiol (1985) 2012; 113: 498-506.

20. Golbidi S, Laher I. Molecular mechanisms in exercise-induced cardioprotection. Cardiol Res Pract 2011; 2011: 972807.

21. Lennon SL, Quindry JC, French JP, Kim S, Mehta JL, Powers SK. Exercise and myocardial tolerance to ischaemia-reperfusion. Acta Physiol Scand 2004; 182: $161-169$.

22. Akita Y. Protein kinase C-epsilon (PKC-epsilon): Its unique structure and function. J Biochem 2002; 132: 847-852.

23. Budas GR, Churchill EN, Mochly-Rosen D. Cardioprotective mechanisms of PKC isozyme-selective activators and inhibitors in the treatment of ischemia-reperfusion injury. Pharmacol Res 2007; 55: $523-536$

24. Carson LD, Korzick DH. Dose-dependent effects of acute exercise on PKC levels in rat heart: Is PKC the heart's prophylactic? Acta Physiol Scand 2003; 178: 97-106.

25. Newton AC. Protein kinase C: Structural and spatial regulation by phosphorylation, cofactors, and macromolecular interactions. Chem
Rev 2001; 101: 2353-2364.

26. Ping P, Song C, Zhang J, Guo Y, Cao X, Li RC, et al. Formation of protein kinase $\mathrm{C}$ (epsilon)-Lck signaling modules confers cardioprotection. J Clin Invest 2002; 109: 499-507.

27. Naitoh K, Yano T, Miura T, Itoh T, Miki T, Tanno M, et al. Roles of $\mathrm{Cx} 43$-associated protein kinases in suppression of gap junctionmediated chemical coupling by ischemic preconditioning. Am J Physiol Heart Circ Physiol 2009; 296: H396-H403.

28. Miura T, Yano T, Naitoh K, Nishihara M, Miki T, Tanno M, et al. Delta-opioid receptor activation before ischemia reduces gap junction permeability in ischemic myocardium by PKC-epsilon-mediated phosphorylation of connexin 43. Am J Physiol Heart Circ Physiol 2007; 293: H1425-H1431.

29. Parekh DB, Ziegler W, Parker PJ. Multiple pathways control protein kinase C phosphorylation. EMBO J 2000; 19: 496-503.

30. Doble BW, Ping P, Kardami E. The epsilon subtype of protein kinase C is required for cardiomyocyte connexin- 43 phosphorylation. Circ Res 2000; 86: 293-301.

31. Shave R, Ross P, Low D, George K, Gaze D. Cardiac troponin I is released following high-intensity short-duration exercise in healthy humans. Int J Cardiol 2010; 145: 337-339.

32. Lu Z, Liu D, Hornia A, Devonish W, Pagano M, Foster DA. Activation of protein kinase $\mathrm{C}$ triggers its ubiquitination and degradation. $\mathrm{Mol}$ Cell Biol 1998; 18: 839-845.

33. Goode NT, Hajibagheri MA, Parker PJ. Protein kinase C (PKC)-induced PKC down-regulation. Association with up-regulation of vesicle traffic. J Biol Chem 1995; 270: 2669-2673.

34. Chmura SJ, Dolan ME, Cha A, Mauceri HJ, Kufe DW, Weichselbaum $R R$. In vitro and in vivo activity of protein kinase $C$ inhibitor chelerythrine chloride induces tumor cell toxicity and growth delay in vivo. Clin Cancer Res 2000; 6: 737-742.

35. Arnaud C, Joyeux-Faure M, Bottari S, Godin-Ribuot D, Ribuot C. New insight into the signalling pathways of heat stress-induced myocardial preconditioning: Protein kinase Cepsilon translocation and heat shock protein 27 phosphorylation. Clin Exp Pharmacol Physiol 2004; 31: 129-133.

36. Lundmark JL, Ramasamy R, Vulliet PR, Schaefer S. Chelerythrine increases Na-K-ATPase activity and limits ischemic injury in isolated rat hearts. Am J Physiol 1999; 277: H999-H1006. 